\title{
POLYMER ELECTROLYTE MEMBRANE FUEL CELL FROM SULFONATED POLYSTYRENE AND MALEATED NATURAL RUBBER BLEND
}

\author{
Ahmad Nasir Pulungan ${ }^{1,2}$, Basuki Wirjosentono ${ }^{3, *}$, Eddiyanto ${ }^{2}$, Kurniawan ${ }^{4}$, \\ Junifa Layla Sihombing ${ }^{2}$ and Sunit Hendrana ${ }^{5}$ \\ ${ }^{1}$ Chemistry Postgraduate Study Programs, Universitas Sumatera Utara, Medan 20155, Indonesia \\ ${ }^{2}$ Department of Chemistry, Universitas Negeri Medan, Jl. Willem Iskandar Psr. V Medan Estate \\ 20371, Indonesia \\ ${ }^{3}$ Department of Chemistry, Universitas Sumatera Utara, Jl. Bioteknologi No. 1, \\ Medan 20155, Indonesia \\ ${ }^{4}$ National Laboratory for Energy Conversion Technology (B2TKE), Kawasan Puspitek Serpong \\ 620-625, Setu, Tangerang Selatan, Banten, 15314, Indonesia \\ ${ }^{5}$ Research Centre for Chemistry, Indonesian Institute of Sciences, Kompleks Puspitek 452, \\ Serpong, Tangerang Selatan, Banten 15314, Indonesia \\ *E-mail: basuki@usu.ac.id
}

\begin{abstract}
One type of aromatic polymer that has been developed widely as a proton exchange membranes (PEM) for fuel cell applications is sulfonated polystyrene (sPS). In this research, the PEM membrane was prepared through the blending process of sulfonated polystyrene (sPS) and maleated natural rubber (MNR), employing PE-g-MAH compatibilities to enhance the mechanical and conductivity properties. Various amounts of sPS were used, namely $10 \% ; 20 \% ; 40 \%$ and $60 \%$ ratios respectively. The blending process was performed in each dilute solution in the polymer, followed by a steam and casting process at particular temperatures. The membrane produced was investigated with FT-IR spectroscopy, scanning electron microscopy (SEM), dynamic mechanical analysis (DMA), water uptake and impedance analysis. The results reveal that by increasing the concentration of $s P S$, lead to the declining of membrane $T_{g}$ values, indicating the high interaction between membrane-forming polymers. The membrane preparation with a concentration of SPS $\geq 40 \%$, which is in the MNR-sPS $40 \%$ and MNR-sPS $60 \%$ membranes show better elasticity. On the other hand, the membrane prepared with $40 \%$ of sPS (MNR-sPS $40 \%$ ) gives the highest proton conductivity of $3.37 \times 10-2 \mathrm{~S} \mathrm{~cm}-1$, implying the potential to be applied as a PEM fuel cell membrane.
\end{abstract}

Keywords: Proton Exchange Membranes, Sulfonated Polystyrene, Maleated Natural Rubber, Proton Conductivity.

(C) RASĀYAN. All rights reserved

\section{INTRODUCTION}

As widely known, the Proton exchange membrane fuel cell (PEMFC) is one type of fuel cell which is vastly used in practical applications. ${ }^{1}$ PEMFC is preferred for several applications because it produces low emissions, has a low operating temperature, and high efficiency, ${ }^{2}$ making this technology is very suitable for various applications on vehicles, portable and stationary. ${ }^{3}$ The most common polymer electrolyte membranes (PEM) for PEMFC used are membranes made from perfluorinated copolymers under the trademark of Nafion ${ }^{\circledR}$. 4,5 Nafion gives high mechanical strength, high oxidative and hydrolytic stability, high ion conductivity, ${ }^{6,7}$ and low water swelling properties. ${ }^{8}$ However, the development of the

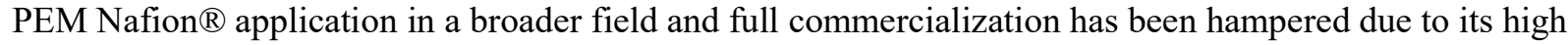

Rasayan J. Chem., 13(2), 1112-1123(2020)

http://dx.doi.org/10.31788/RJC.2020.1325616

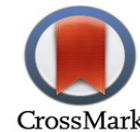


RASĀYAN J. Chem.

Vol. 13 | No. 2 |1112 - 1123| April - June | 2020

costs, conductivity lost at high temperatures $\left(>80^{\circ} \mathrm{C}\right)$, and high permeability to result in fuel cross over. Therefore, novel alternatives are urgently required to address these issues.

To date, various proton conductor polymer membranes have been constructed and modified to produce a more economical alternative PEM membrane, with higher operating temperatures and proton conductivity and lower methanol permeability. These membranes can be classified as inorganic-organic composite membranes, sulfonated hydrocarbon polymer membranes, mixed polymer membranes and acid-base polymer membranes. For each type of membranes, they possess various strengths and advantages. Aromatic hydrocarbon-based polymers have good stability against heat and oxidative environment, ${ }^{9}$ good mechanical properties and low costs. ${ }^{10}$ Sulfonated polystyrene, on the other hand, (sPS) is one type of aromatic polymer that has been developed for PEMFC alternative membranes. ${ }^{1,3,10-14}$ However, polystyrene has problems with its fragile structure at a temperature of $100-120^{\circ} \mathrm{C}$. On the other hand, the $\mathrm{SO}_{3} \mathrm{H}$ group which is only attached to the polystyrene structure, will make it difficult to form a cluster structure, so that the membrane is not able to produce optimal proton conductivity. Therefore, the sPS membrane requires a matrix that can lead to the formation of proton transport pathways from the $-\mathrm{SO}_{3} \mathrm{H}$ group, and can also contribute in increasing the chemical and mechanical properties of membranes, for it is very important for membrane applications in the fuel cell.

In this research, efforts to improve the mechanical properties of sPS membranes using natural polymer materials available in Indonesia, namely natural rubber (NR) as a matrix has been performed. NR has physical properties; assertiveness, elastic and high tensile strength ${ }^{15,16}$ and has been widely used in the thin film industry. ${ }^{17}$ Excellent NR elasticity is expected to improve the physical properties of fragile sPS. To form a membrane along with the sPS, NR needs to be modified to form maleated natural rubber (MNR) with the MAH grafting process. The formation of sPS and MNR membranes was conducted by blending and casting methods. The succinic acid group from the MNR is expected to direct the sulfonate groups in the proton transport through the formation of hydrogen bonds between the succinate group (anhydride group) and the sulfonate group. Research related to this has been carried out on the formation of PEM membranes from sPS with PE-g-MAH. The blending process was performed by dissolving the two constituent materials in a much diluted solution, and the sulfonate group direction is carried out in a liquid condition. The application of this method in manufacturing membranes results in better bonding interactions between polymers. ${ }^{18}$

The effort to tackle the fragile properties of SPS membranes using maleated natural rubber (MNR) as a matrix and PE-g-MAH is considered to be novel. Thus, it is expected to produce a solid and homogeneous membrane with better mechanical properties. The proton membrane transport pathway is formed from an H-bonding sulfonate group from the sPS with anhydride group from the MNR. Efforts to increase membrane conductivity through the formation of a straight long chain of hydrogen bonds between sulfonate groups and anhydride groups produce rod-structured as shown in Fig.-1. To achieve this, the blending process is carried out in a very dilute solution with a slow stirring technique.

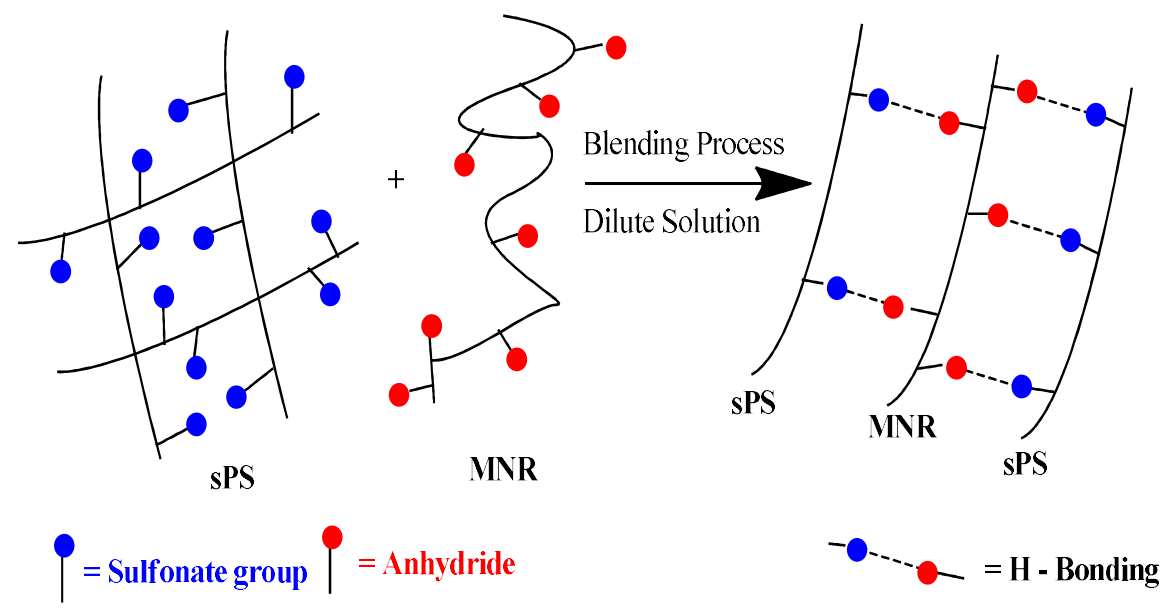

Fig.-1: The Rod-like Structure Formation Scheme Via Hydrogen Bonding 
RASĀYAN J. Chem.

Vol. 13 | No. 2 |1112 - 1123| April - June | 2020

\section{Material}

\section{EXPERIMENTAL}

Sulfonated polystyrene (sPS) was obtained from P2F-LIPI, prepared by following the procedure of Hendrana et al. ${ }^{2}$ The sulfonation degree (DS) of sPS was determined by the acid-base titration method according to the literature. ${ }^{19}$

The $60 \%$ concentrated latex (HANR) DRC was purchased from PT. IKN-Medan. PE-g-MAH was purchased from Aldrich $(\sim 0.5 \mathrm{wt} . \%)$. Solvents of methanol, acetone, toluene, xylene, are p. a grade and purchased from Merck. Also, Sodium dodecyl sulfate (SDS: 99\%), urea (99\%), maleic anhydride (MAH: 99\%), benzoyl peroxide (BPO) were purchased from Merck. $\mathrm{NaOH}$ and Phenolphthalein (PP), nitrogen and liquid nitrogen indicators were obtained from PT. Aneka Gas.

\section{Natural Rubber Modification}

The NR modification was conducted to form MNR through the MAH grafting process. In the initial stage, concentrated latex DRC was treated with a deproteinization process, following the procedure of Fukuhara et al., ${ }^{20}$ resulting DPNR DRC 30\%. The DPNR DRC 30\% latex was inserted into the copolymerization reactor and stirred for 30 minutes while nitrogen gas flowed. Then, MAH monomers were added slowly and stirred continuously, followed by the addition of the initiator benzoyl peroxide (BPO). The reaction process was left for 3 hours at a temperature of $\pm 70^{\circ} \mathrm{C}$ along with the stirring process and flowing of nitrogen gas. The reaction product was then agglomerated in a methanol solvent. The lumps were formed and then pressed, sliced into small pieces, then dried in a geer oven at $45^{\circ} \mathrm{C}$ for 24 hours. The obtained MNR product was characterized by FT-IR and the value of the degree of grafting was determined.

Determination of the value of grafting degree was carried out by the titration method following the procedure performed by. ${ }^{21}$ The calculation of $\mathrm{Dg} \%$ is based on the equation:

$$
D_{g}(\%)=\frac{(V t-V b) \times C t \times E w}{2 W} \times 100 \%
$$

Where, Ew is the molecular weight of MAH ( $98 \mathrm{~g} / \mathrm{mole})$, the $\mathrm{Ct}$ is the concentration of $\mathrm{KOH}(\mathrm{mole} / \mathrm{L})$ in methanol/ benzyl alcohol, $\mathrm{Vt}$ and $\mathrm{Vb}(\mathrm{mL})$ is $\mathrm{KOH}$ Volume used for the sample test and blank test respectively, and $\mathrm{W}(\mathrm{g})$ is the weight of the sample.

\section{Membrane Preparation}

The process of membrane preparation was carried out by the blending and casting method in a dilute solution system. The sPS was dissolved in toluene: methanol with a ratio of (9: 1) at $45^{\circ} \mathrm{C}$ and slowly stirred with a magnetizing stirrer to obtain dilute solution. Each MNR and PE-g-MAH were dissolved in toluene and mixed with a magnetic stirrer at $45{ }^{\circ} \mathrm{C}$ until the dilute solution was obtained. The MNR solution was added with PE-g-MAH solution slowly followed by a stirring process until a homogeneous solution was obtained and followed by dropwise of sPS solution addition and slowly stirred continuously at $45^{\circ} \mathrm{C}$ for 8 hours. The blending solution of MNR-sPS-PE-g-MAH was produced and then cast on a petri dish. The blend was slowly evaporated on the geer oven for \pm 48 hours at $45^{\circ} \mathrm{C}$. Finally, the MNRsPS-PE-g-MAH film layer obtained was then vacuum dried at $60^{\circ} \mathrm{C}$ for 8 hours.

Table-1: The Composition Variation of Membranes

\begin{tabular}{c|c|c}
\hline \multicolumn{2}{|c|}{ Composition (\%) } & Sample Code \\
\hline 10 & 90 & MNR-sPS $10 \%$ \\
\hline 20 & 80 & MNR-sPS $20 \%$ \\
\hline 40 & 60 & MNR-sPS $40 \%$ \\
\hline 60 & 40 & MNR-sPS $60 \%$ \\
\hline
\end{tabular}

\section{Membrane Characterization}

The membrane characterization including analysis with Fourier Transformed-Infra (FT-IR) measurements was carried out using Alpha Bruker Spectrophotometer type. The FT-IR spectra of samples were scanned from 4000 to $500 \mathrm{~cm}^{-1}$. 
RASĀYAN J. Chem.

Vol. 13 | No. 2 |1112 - 1123| April - June | 2020

Morphological analysis with SEM Zeiss type EPOMH 10 Zss was conducted to observe the homogeneity and porosity of membrane-based on imaging on the surface and cross-section. Furthermore, to investigate the spread of sulfonate groups on membranes, SEM-Map analysis was performed.

The membrane tension strength was conducted by using Hitachi DMA 7100. The test was carried out using a tension-type attachment. The sample was measured in dimensions, then placed on an attachment. Test temperature was carried out at $-80^{\circ} \mathrm{C}$ up to $350^{\circ} \mathrm{C}$ with a heating rate of $2 \mathrm{~K} / \mathrm{min}$ using nitrogen gas. Tests were carried out at various frequencies, namely $1 ; 2 ; 5 ; 10$ and $20 \mathrm{~Hz}$ respectively with a given load of $0.5 \mathrm{~N}$. The results of measurement were obtained in the form of graphic of Storage modulus (E'), loss modulus $\left(E^{\prime \prime}\right)$ and tangent delta $(\delta)$ as a function of temperature.

The membrane water uptake test was performed to determine the absorbency of the membrane to the water. Membrane samples were firstly dried in the oven at a temperature of $40^{\circ} \mathrm{C}$ to obtain the dry weight of the membrane (Wdried). The dried membrane samples were immersed in water for 24 hours at room temperature. After that, the water was removed (wiped with tissue), then weighed. Therefore, the wet weight of the membrane (Wwet) could be obtained. ${ }^{22,23}$ Lastly, the water uptake is calculated using eqn.-2 as follows ${ }^{24}$ :

$$
\% \text { Water uptake }=\frac{\mathrm{W}_{\mathrm{wet}}-\mathrm{W}_{\mathrm{dr}}}{\mathrm{W}_{\mathrm{dry}}} \times 100 \%
$$

The proton conductivity test was carried out to investigate the $\mathrm{H}^{+}$conductivity or cation exchange indicator of the membrane. Measurements were made using the chemical impedance meter of HIOKI 3532-BO type with a frequency of $10^{-1}-10^{6} \mathrm{~Hz}$, and a voltage of $1000 \mathrm{mV}$. Membrane samples were measured in a hydrated (wet) state at $25^{\circ} \mathrm{C}$. The sample was previously immersed in water (in this research, $1 \mathrm{M} \mathrm{H}_{2} \mathrm{SO}_{4}$ solution was used) for \pm 6 hours before measurement. ${ }^{25}$ The value of membrane conductivity is calculated by eqn.-3, namely:

$$
\sigma=\frac{\mathrm{d}}{\mathrm{RA}}
$$

Where, $\mathrm{d}=$ membrane sample thickness, $\mathrm{R}=$ membrane resistance, and $\mathrm{A}=$ Surface membrane area.

From the measurement of the proton conductivity of the sample, the graph would be generated by projecting the real impedance $(\mathrm{Z})$ on the $\mathrm{X}$-axis and the imaginary impedance $(\mathrm{Zi})$ on the $\mathrm{Y}$-axis.

\section{RESULTS AND DISCUSSION}

Figure-2 shows the FTIR spectrum from MNR and sPS. The absorption peaks characteristic of natural rubber in figure 1.a was observed in several wave number, namely, at $2960 \mathrm{~cm}^{-1}(\mathrm{C}-\mathrm{H}), 1625-1663 \mathrm{~cm}^{-1}$ for $\mathrm{C}=\mathrm{C}$ stretching, $1446 \mathrm{~cm}^{-1}$ corresponds to $-\mathrm{CH}_{2}$ - stretching, $1375 \mathrm{~cm}^{-1}\left(-\mathrm{CH}_{3}\right)$, and $839 \mathrm{~cm}^{-1}$ represents the deformation of $=\mathrm{CH}^{26-28}$

The weak absorption peak at around $1730 \mathrm{~cm}^{-1}$ is a vibrational stretch of $\mathrm{C}=\mathrm{O}$ from succinic anhydride or succinic MAH acid from the MNR.

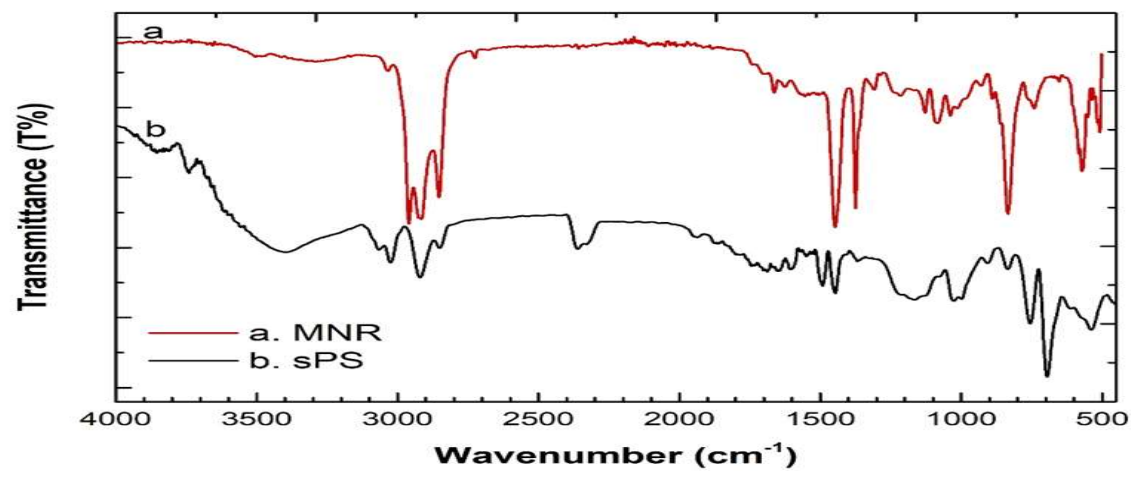

Fig.-2The FTIR Spectra of MNR and sPS 
RASĀYAN J. Chem.

Vol. 13 | No. 2 |1112 - 1123| April - June | 2020

On the other hand, the FTIR spectrum of sPS is presented in figure 1.b. The absorptions of sulfonate groups at sPS reveal various wave numbers, namely at $1019.40 \mathrm{~cm}^{-1}$ for symmetric SO3 strain vibrations and $1166.95 \mathrm{~cm}^{-1}$ for strain vibrations of $-\mathrm{S}=\mathrm{O}$. The absorption at wavenumbers of $834.23 \mathrm{~cm}^{-1}$ and 756 $\mathrm{cm}^{-1}$ indicates that the sulfonate group bonded to the aromatic ring at the position of para and ortho. The absorption of the hydroxyl group was observed in the wavenumber of $3399.60 \mathrm{~cm}^{-1}$ which proved that there was an $\mathrm{O}-\mathrm{H}$ bond in the $\mathrm{SO}_{3} \mathrm{H}$ group. These are consistent with those reported by ${ }^{2,12}$. Furthermore, the absorption at $1027 \mathrm{~cm}^{-1} ; 1080 \mathrm{~cm}^{-1}$ results from the symmetric stretching vibration of $\mathrm{SO}_{3} \mathrm{H}$ groups, and the absorption at $1157 \mathrm{~cm}^{-1}$ and $1180 \mathrm{~cm}^{-1}$ results from a sulfonate anion attached to a phenyl ring. The results of measurements of sulfonation degree (DS) from sPS were obtained to be $56.52 \%$.

The membrane films produced are shown in Fig.-3 below. The FT-IR characterization of membranes was carried out to identify the interaction of membrane-forming polymers based on the analysis of functional group absorption. The analysis was also carried out at wavenumbers from $4.000 \mathrm{~cm}^{-1}$ to $400 \mathrm{~cm}^{-1}$. The peak characteristics of the spectrum of each membrane are shown in Fig.-4.

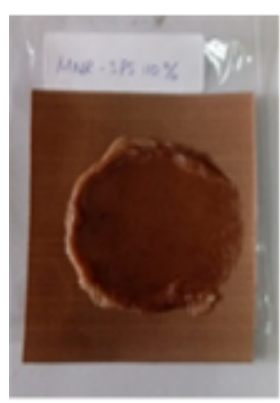

(a)

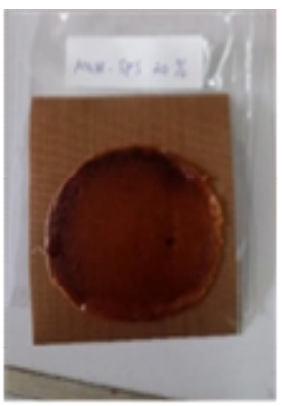

(b)

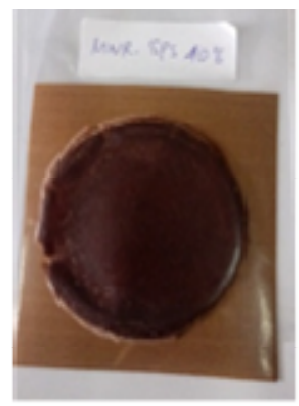

(c)

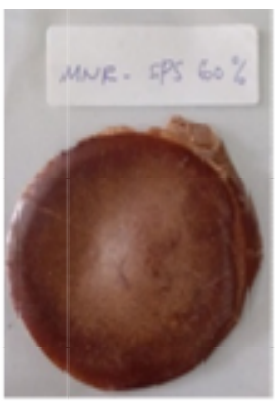

(d)

Fig.-3:The Prepared Membranes of MNR-sPS-PE-g-MAH with Various sPS Concentrations of (a) 10\%, (b) 20\%, (c) $40 \%$ and (d) $60 \%$

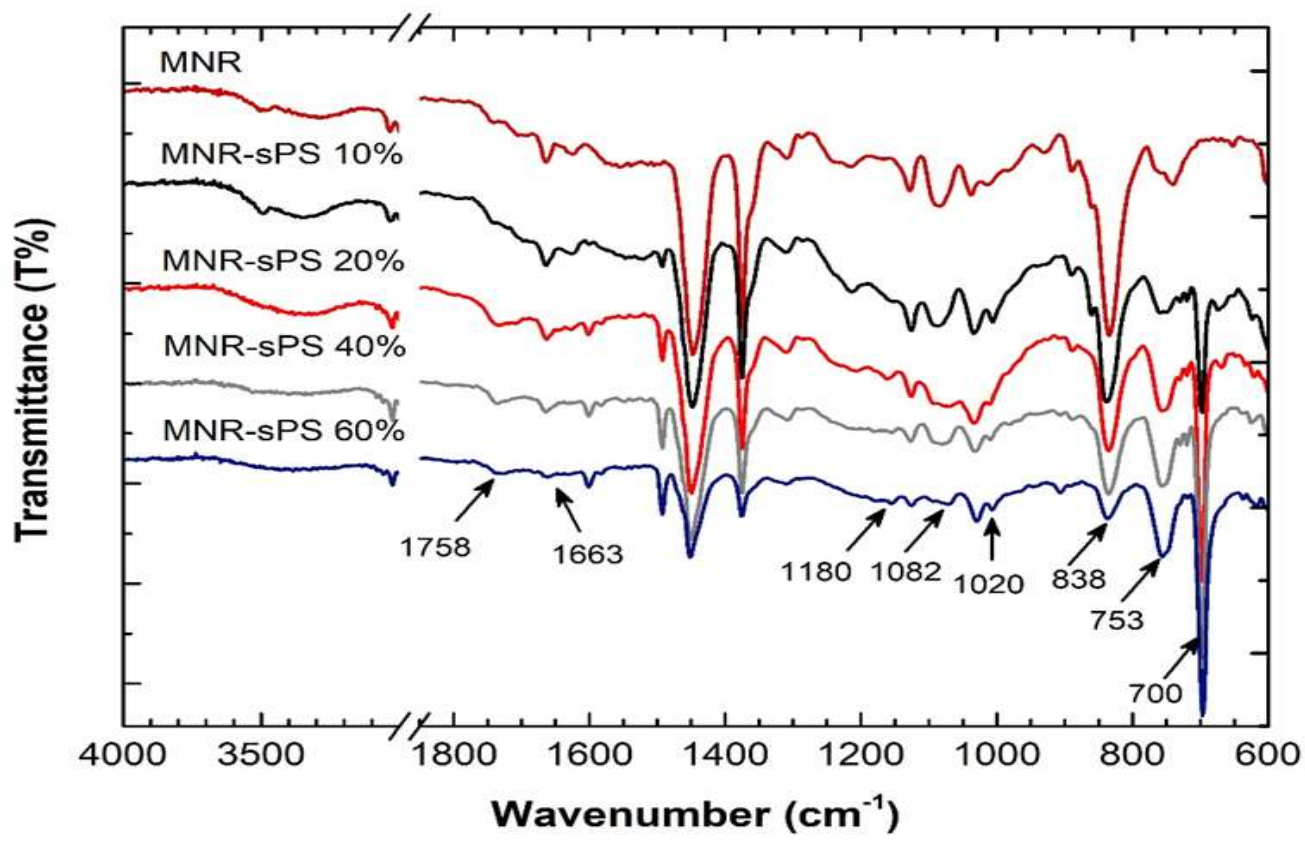

Fig.-4: The FTIR Spectra of All Prepared Membranes with Different sPS Concentrations 
RASĀYAN J. Chem.

Vol. 13 | No. 2 |1112 - 1123| April - June | 2020

The absorption peaks for each membrane are shown in Fig.-3, with different intensities observed at wavenumbers of $700 \mathrm{~cm}^{-1}$ to $1300 \mathrm{~cm}^{-1}$. The absorption intensity increased sharply with the increase in sPS concentration observed at wavenumbers around $700 \mathrm{~cm}^{-1}$ and $753 \mathrm{~cm}^{-1}$ which correspond to $\mathrm{C}-\mathrm{H}$ bonds in benzene mono substituents and substituted aromatic rings sourced from sPS. The decreased absorption intensity was observed at a wavenumber of about $838 \mathrm{~cm}^{-1}$. The absorption intensity at this wavenumber decreases with increasing of sPS concentration. A similar trend is shown by the absorption of the carbonyl group $(\mathrm{C}=\mathrm{O})$ at around $1600 \mathrm{~cm}^{-1}-1800 \mathrm{~cm}^{-1}$. Meanwhile, the shift in vibration absorption of symmetrical stretching of the $-\mathrm{SO}_{3} \mathrm{H}$ group was observed at wavenumbers of $1020 \mathrm{~cm}^{-1}$, $1082 \mathrm{~cm}^{-1}$ and absorption peaks at around $1150 \mathrm{~cm}-1$ and $1180 \mathrm{~cm}^{-1}$.

This result is in accordance with, ${ }^{29}$ reported that absorption at $1027 \mathrm{~cm}^{-1} ; 1080 \mathrm{~cm}^{-1}$ resulted from the symmetric stretching vibration of $\mathrm{SO}_{3} \mathrm{H}$ groups, and the absorption at $1157 \mathrm{~cm}^{-1} ; 1180 \mathrm{~cm}^{-1}$ results from a sulfonate anion attached to a phenyl ring. This data shows the occurrence of interactions in the formation of H-bonding bonds between sulfonate groups from sPS and anhydride groups from MNR. Moreover, this data is convinced by the absorption of the $\mathrm{OH}$ group at a wavenumber of $3200 \mathrm{~cm}^{-1}$ even though with the widening peak.

\section{Morphological Structure of MNR-sPS-PE-gMAH Membrane}

Figure-5 is the analysis result of the morphological structure for each membrane with SEM analysis. It is shown that the cross-section of the MNR-sPS 10\% membrane and MNR-sPS 20\% appear to be solid but observably not homogeneous due to the grainy component of sPS. On the other hand, the MNR-sPS $40 \%$ membrane has a cross-section with a porous layer on the part membrane sub-layer and MNR-sPS $60 \%$ membrane has a cross-section that appears porous with a smaller and homogeneous size. Homogeneity of the membrane is very influential in the spread of sulfonate groups on each part of the membrane. The spread of sulfonate group in each membrane was then analyzed by SEM Mapping. The results obtained are displayed in Fig.-6.

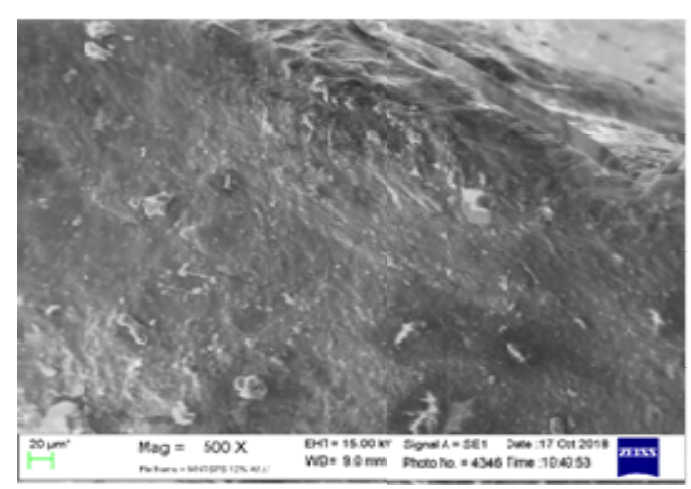

(a)

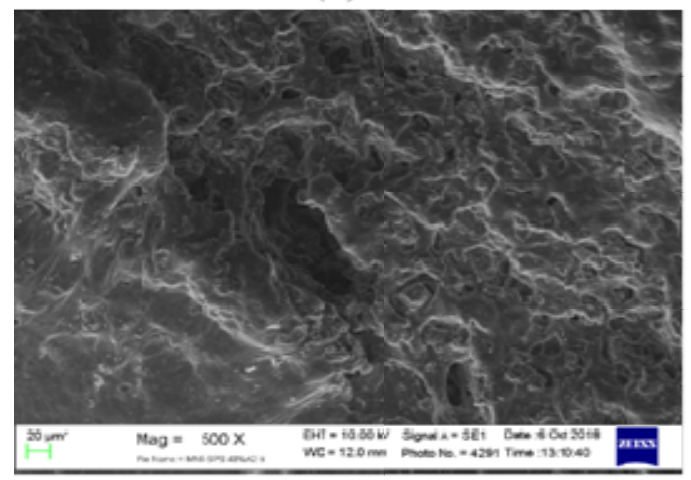

(c)

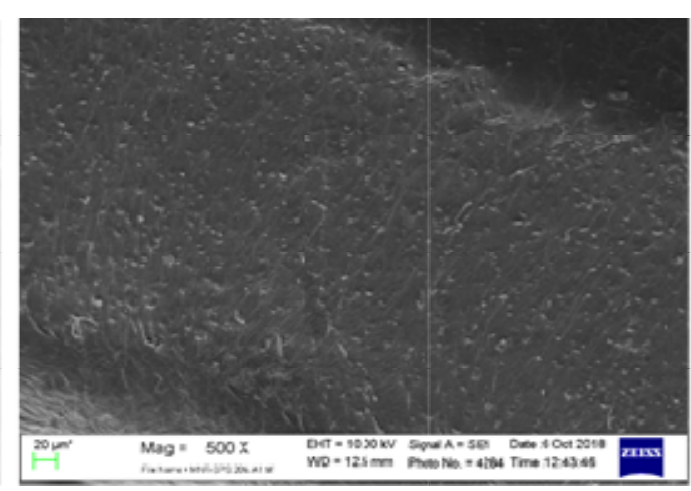

(b)

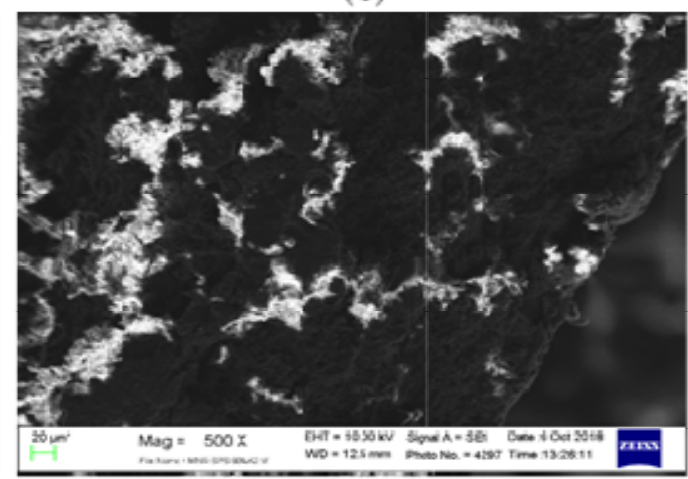

(d)

Fig.-5: The Morphological ImageS of (a) MNR-sPS 10\%, (b) MNR-sPS 20\%, (c) MNR-sPS 40\% and (d) MNRsPS $60 \%$ with 500x Magnification 
RASĀYAN J. Chem.

Vol. 13 | No. 2 |1112 - 1123| April - June | 2020

The spread of sulfonate groups from sPS on the membrane surface was identified by SEM-Mapping analysis. The distribution of the sulfonate group can be identified as the element (S) in blue and oxygen (O) in green. The surface SEM-map imaging results of the 10\% MNR-sPS membrane and 20\% MNR-sPS in Fig.-5(a) and 5(b) show that the sulfonate groups are not homogeneously dispersed on each membrane, while the surface of the 40\% MNR-sPS membrane and 60\% MNR-sPS membrane in Fig.-5(c) and 5(d) indicate that sulfonate groups are more homogeneously distributed on membranes. The presence of nonhomogeneous sulfonate groups in each part of the membrane can inhibit the flow of protons which can reduce membrane proton conductivity. Thus, this correlates with the conductivity data of each membrane presented in Table-3.

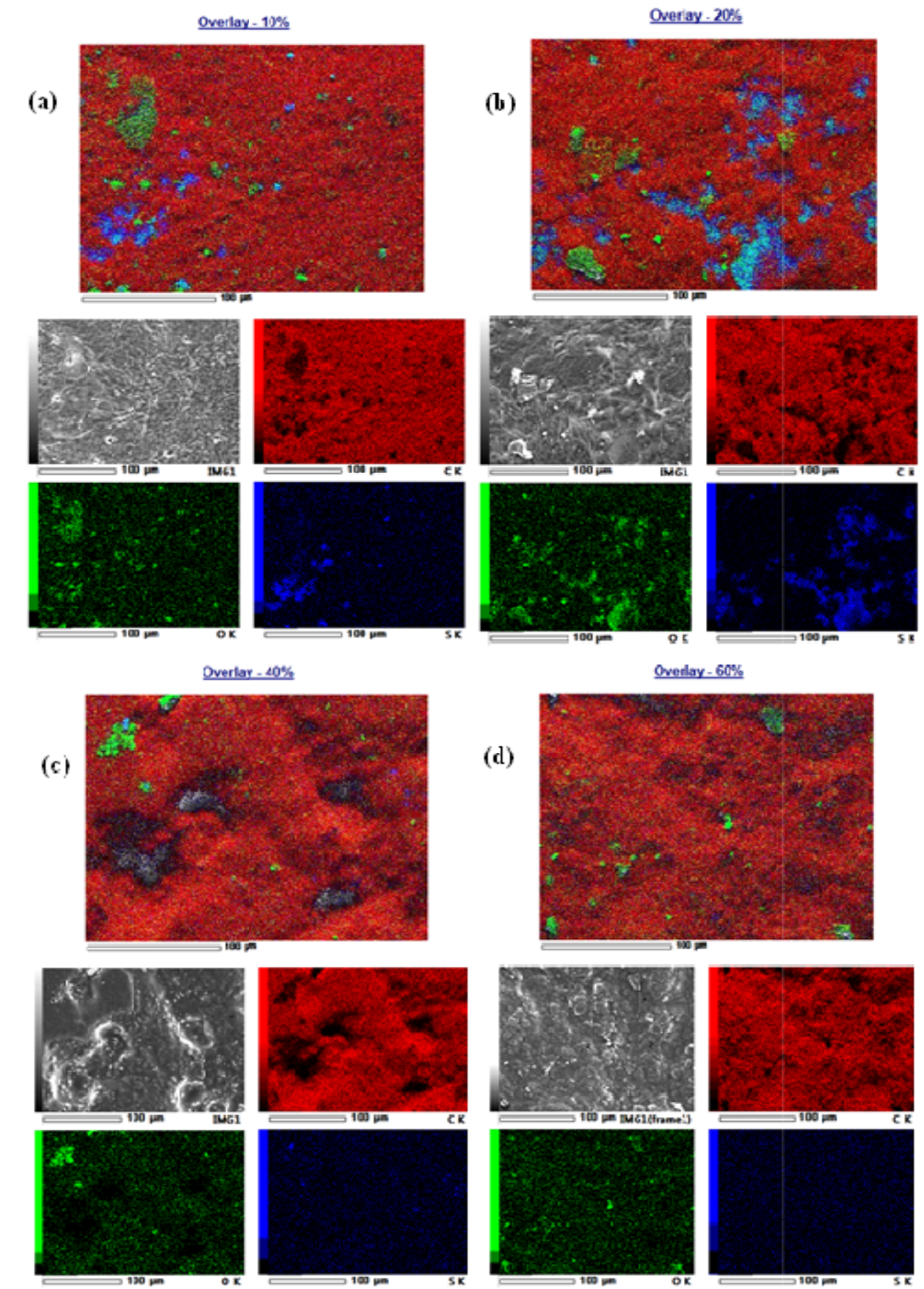

Fig.-6:The Result of SEM-Map of Various Membrane; (a) MNR-sPS 10\%, (b) MNR-sPS 20\%, (c) MNR-sPS 40\% and (d) MNR-sPS 60\% 
RASĀYAN J. Chem.

Vol. 13 | No. 2 |1112 - 1123| April - June | 2020

Thermo-mechanical Properties of the Membranes

The comparison of the DMA curve of each membrane (a) MNR-sPS 10\%, (b) MNR-sPS 20\%, (c) MNRsPS 40\%, (d) MNR-sPS 60\% are shown in Fig.-7. Figure-7(a) shows that the difference in sPS concentration used in membrane formation has an influence on changes in the modulus storage of membranes produced. The use of sPS at concentrations of $10 \%$ and $20 \%$ in each membrane of MNR-sPS $10 \%$ and MNR-sPS $20 \%$, increases storage modulus above the glass transition temperature $\left(\mathrm{T}_{\mathrm{g}}\right)$. This is due to the strong interaction between sPS and MNR in the membrane. The existence of a strong interfacial action between rubber (as a matrix) and filler material increases the composite modulus storage. $^{30}$

However, in membranes with sPS concentrations of $40 \%$ and $60 \%$, it shows a decrease in membrane modulus storage produced. This indicates that the difference in sPS concentration produces different dispersions, resulting in membrane modulus storage with MNR-sPS $20 \%>10 \%>40>60 \%$ respectively. These data correlate with the rigidity of the membrane which is presented in the form of a modulus loss curve. From Fig. $-7($ b), it can be seen that the MNR-sPS $20 \%$ membrane with sPS $20 \%$ shows the highest stiffness (membrane modulus loss with MNR-sPS 20\%> MNR-sPS10\%> MNR-sPSeq $40>$ MNR-sPS $60 \%)$.

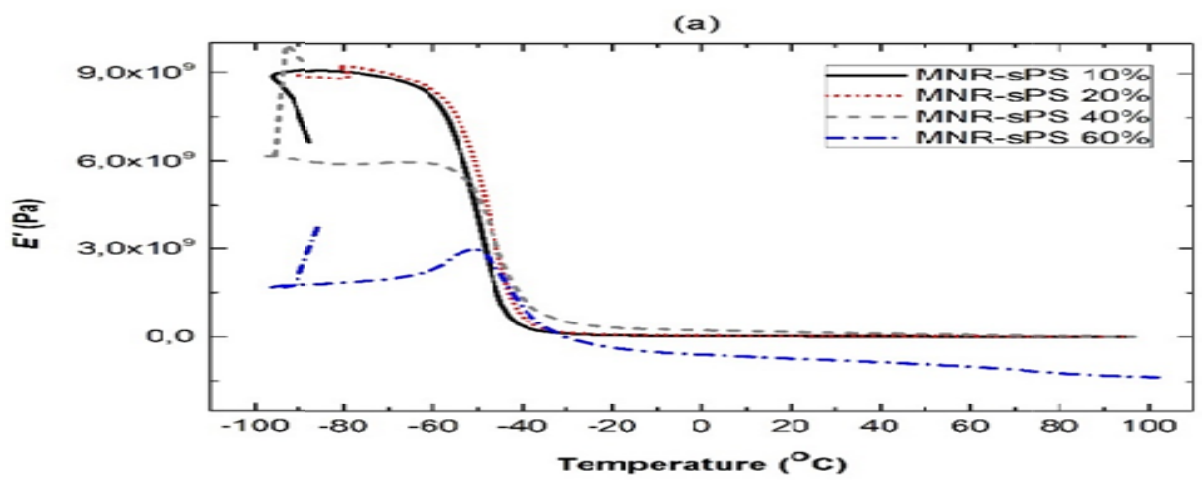

(b)
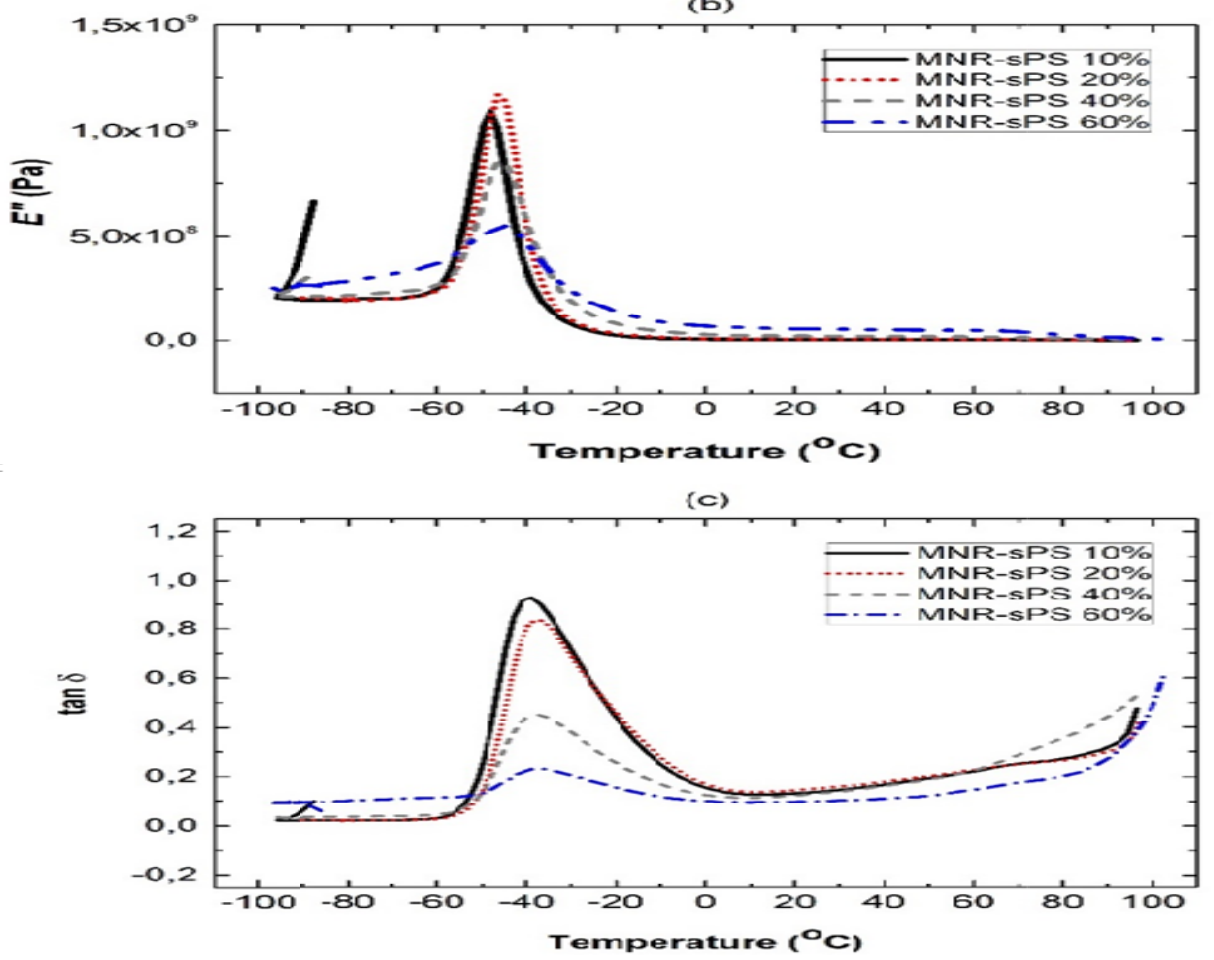

Fig.-7: The Curves of (a) Storage Modulus (E'), (b) Loss Modulus (E') and (c) Tan $\delta$ as a Temperature Function of Membranes

1119 
RASĀYAN J. Chem.

Vol. 13 | No. 2 |1112 - 1123| April - June | 2020

Table-2: $T_{g}$ Membrane Value Change through DMA Analysis $(* 31, * *$ DSC method)

\begin{tabular}{c|c}
\hline Sample Code & $T_{g}\left({ }^{\circ} \mathrm{C}\right)$ \\
\hline NR $*$ & -70 \\
\hline MNR $* *$ & $-59,35$ \\
\hline MNR-sPS $10 \%$ & $-40,14$ \\
\hline MNR-sPS $20 \%$ & $-37,83$ \\
\hline MNR-sPS 40\% & $-37,45$ \\
\hline MNR-sPS $60 \%$ & $-37,07$ \\
\hline
\end{tabular}

The tan $\delta$ peaks were observed in the temperature range of $-60^{\circ} \mathrm{C}$ to $20^{\circ} \mathrm{C}$, which is the transition area shown in Fig.-7(c). The use of sPS concentrations at greater concentrations in the formation of MNR-sPS $40 \%$ and MNR-sPS $60 \%$ membrane decreases $\tan \delta$. The decreasing tan peaks $\delta$ indicate an increase in membrane elasticity. ${ }^{32}$ Schon et al., (2002) reported that increasing the elastic properties of silicate composites with natural rubber matrices can be observed by decreasing the tan curve $\delta .{ }^{33}$ The MNR-sPS $60 \%$ membrane has the lowest $\tan \delta$, so that it has the highest elastic properties among the other membranes. Physically, the sPS membrane has brittle properties. However, the use of sPS concentrations at $40 \%$ to $60 \%$ gives a very high increase in the elastic properties of the membrane. The increase like this elasticity can be due to the increase in the interaction of sPS and MNR in the formation of H-Bonding bonds effectively. This can be seen from the change in the value of the glass transition temperature (Tg). In addition, this data correlate with previous FTIR and SEM-map results.

The changes in Tg value of membrane obtained from the DMA curve can be determined from changes in the modulus storage deviation curve ( $\left.E^{\prime}\right)$, maximum peak loss modulus ( $\left.E^{\prime \prime}\right)$ and $\tan \delta .{ }^{34}$ In this research, the determination of Tg membrane were determined from the maximum peak of $\tan \delta$. Tg is a temperature that indicates a relaxation process in a polymer, in which the material changes from glassy material to rubbery material. ${ }^{35}$ Data on Table-2 show that an increase in the concentration of sPS on the membrane results in a decrease in the value of $\mathrm{Tg}$ membrane. This is understood as a result of effective interaction between MNR and sPS. Figure-7 illustrates the storage modulus (E'), loss modulus (E') and damping factor $(\tan \delta$ ) with different $\mathrm{Tg}$ values. The difference is presumed because of the complex dynamic thermomechanical properties of the MNR-sPS membrane produced. Baboo et al. ${ }^{36}$ reported that the thermomechanical properties of composites are strongly influenced by the mechanical dynamics of the matrix, fillers and interface bonds. Moreover, Carone et al., ${ }^{31}$ reported that the Tg NR value was around $70^{\circ} \mathrm{C}$. The results of the measurement of MNR Tg with DSC were obtained as 59.35, while the membrane showed the lowest $\mathrm{Tg}$ value in the MNR-sPS membrane of $60 \%$ is at $-37.07^{\circ} \mathrm{C}$.

\section{Conductivity and Water Uptake Performance}

The data from conductivity measurements of each membrane: (a) 10\% MNR-sPS, (b) 20\% MNR-sPS, (c) $40 \%$ MNR-sPS, (d) 60\% MNR-sPS with chemical impedance meter result in the value of imaginary impendence $(\mathrm{Zi})$ and real impedance $(\mathrm{Z})$ projected in graphical form, so that the Ny-quist graph will be obtained as displayed in Fig.-8. The measurement results with Chemical impedance meter were processed by using Hioki LCR sample program software to obtain membrane resistance values, so that membrane conductivity values can be obtained. The conductivity value of each membrane is described in Table-3.

The data in Table-3 shows that in general, the increase in sPS concentration affects increasing membrane conductivity values. The $40 \%$ MNR-sPS and $60 \%$ MNR-sPS membrane each have a proton conductivity value of $3.37 \times 10^{-2} \mathrm{Scm}^{-1}$ and $2.79 \times 10^{-2} \mathrm{Scm}^{-1}$ respectively, approaching the conductivity value of the Nafion membrane which is $4.83 \times 10^{-2} \mathrm{Scm}^{-1}$. It can be indicated that at a greater sPS concentration $(>40 \%)$, the amount of sulfonate groups available is sufficient to increase better interaction between MNR and sPS. This allows the formation of an effective H-bonding bond between the sulfonate group and succinic acid which is evenly distributed/homogeneous on each part of the membrane.

Table-3: The Proton Conductivity and Water Uptake Performance Comparison of Various Membranes with Nafion

\begin{tabular}{c|c|c}
\hline Sample Code & Conductivity $\sigma\left(\mathrm{Scm}^{-1}\right)$ & Water uptake (wt.\%) \\
\hline MNR-sPS $10 \%$ & $6.93 \times 10^{-3}$ & 77.27 \\
\hline MNR-sPS $20 \%$ & $5.23 \times 10^{-3}$ & 113.88 \\
\hline MNR-sPS $40 \%$ & $3.37 \times 10^{-2}$ & 226.02 \\
\hline
\end{tabular}

1120

POLYMER ELECTROLYTE MEMBRANE FUEL CELL 
RASĀYAN J. Chem.

Vol. 13 | No. 2 |1112 - 1123| April - June | 2020

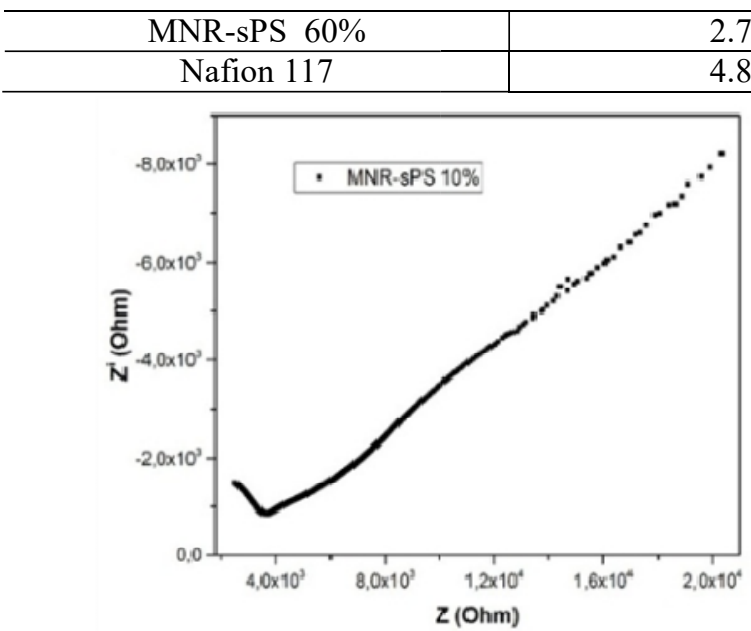

\begin{tabular}{l|c}
$2.79 \times 10^{-2}$ & 353.08 \\
\hline $4.83 \times 10^{-2}$ & 13.18
\end{tabular}
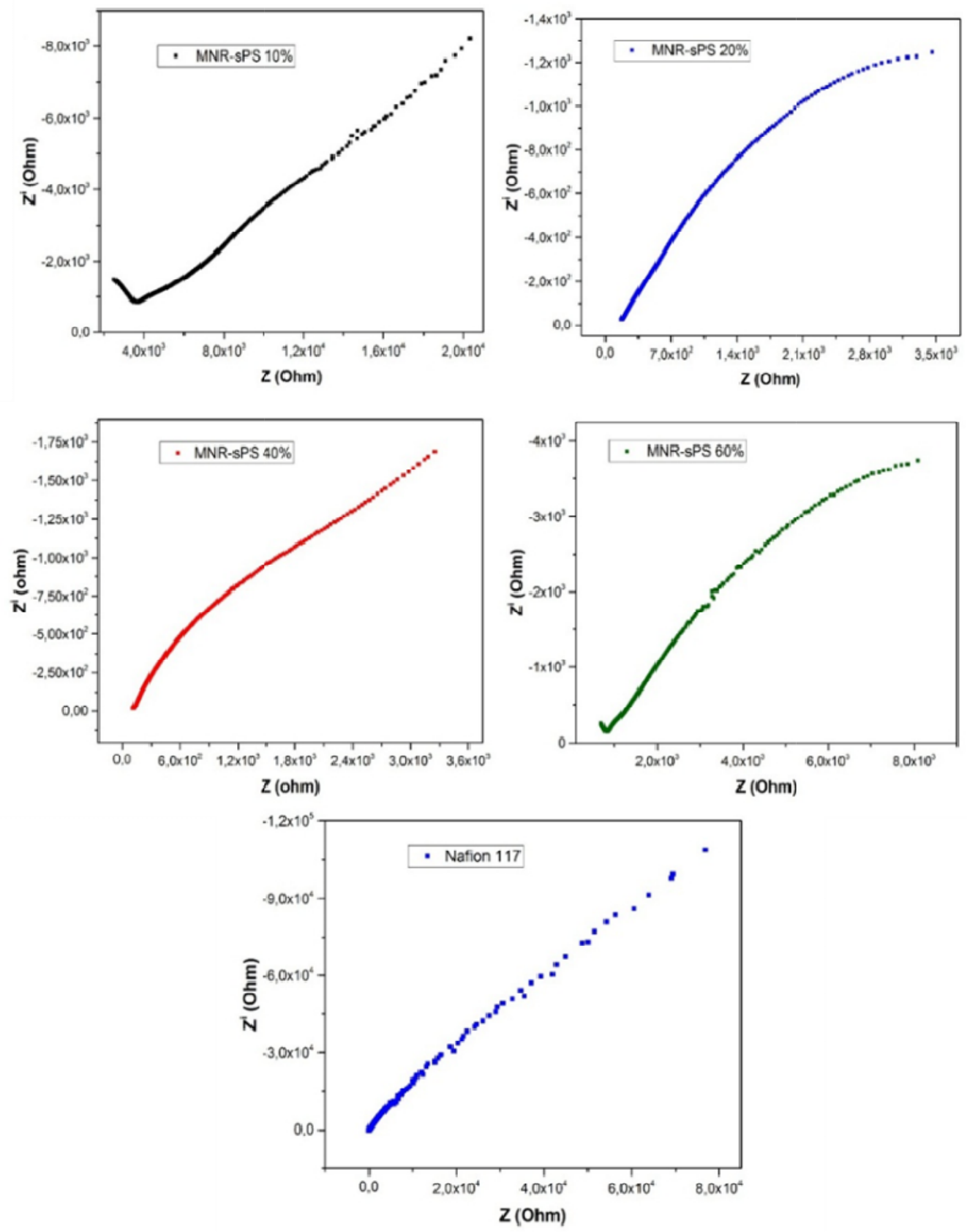

Fig.-8:The Ny-Quist Graph From Varios Membrane of (a) MNR-sPS 10\%, (b) MNR-sPS 20\%, (c) MNR-sPS 40\%, (d) MNR-sPS 60\% and (e) Nafion 117

The H-bonding bond directs the $\mathrm{SO}_{3} \mathrm{H}$ group to be aligned to form the rode-structure as a proton delivery path, so that it increases the conductivity of the proton membrane. On the other hand, for MNR-sPS 10\% and MNR-sPS 20\% membrane, it is likely that the sulfonate group is not aligned but united to form a cluster of sulfonate groups and results for sulfonate group not being distributed homogeneously on each part of the membrane. This statement is in line with the results of the previous SEM-map analysis. This condition can inhibit proton transport, thereby reducing the conductivity of the proton membrane.

On the other hand, an increase in sPS concentration provides increased membrane water uptake. Based on data in table 3 of the MNR-sPS $40 \%$ and MNR-sPS $60 \%$ membrane produces a higher water uptake 
compared to MNR-sPS $10 \%$ and MNR-sPS $20 \%$ membrane. The water adsorbed on the membrane can facilitate the movement of protons, improving membrane performance ${ }^{37,38}$. However, MNR-sPS $60 \%$ membrane conductivity is lower than MNR-sPS $40 \%$ membrane. This can be explained based on reports from ${ }^{39}$ which discovered that membranes with higher water uptake can reduce proton membrane conductivity due to the formation of hydrogen bonds between the water molecules themselves. Also, it can inhibit mobility as proton transport. However, the membrane with high water uptake, in its application, does not require a complicated humidification process.

\section{CONCLUSION}

The PEM from the sPS and MNR using PE-g-MAH were prepared by blending and casting methods in a very dilute solution system. Effective interactions in the formation of H-bonding bonds between sulfonate groups and anhydride groups are produced on membranes with a sPS concentration of $\geq 40 \%$, namely in the MNR-sPS $40 \%$ and MNR-sPS $60 \%$ membrane The H-bonding forms a proton delivery path, so that the sulfonate group is homogeneously distributed and able to increases proton membrane conductivity. The highest conductivity value of the resulting MNR-sPS $40 \%$ is $3.37 \times 10-2 \mathrm{Scm}^{-1}$. Also, the effective interaction of MNR and sPS can improve the mechanical properties of membranes in terms of elastic properties. Furthermore, the membrane produced in is very potential to be developed as PEM for fuel cell applications. On the other hand, the resulting membrane has a fairly high water uptake, making it cheaper to use since it does not require a complicated humidification process.

\section{ACKNOWLEDGMENT}

The authors would like to send gratitude to the Ministry of Research, Technology, and Higher Education of Indonesia for the research funding support via the Doctoral Dissertation Grant Scheme (Contract No. 027/UN33.8/LL/2018). Furthermore, authors also acknowledge Universitas Negeri Medan, Doctoral Program of Chemistry of Universitas Sumatera Utara and Puspitek P2F-LIPI, Indonesia for providing research facilities.

\section{REFERENCES}

1. B. Smitha, S. Sridhar, A. Khan, Journal of Membrane Science, 225(1-2), 63(2003), DOI: $10.1016 / \mathrm{S} 0376-7388(03) 00343-0$

2. S. Hendrana, E.R. Chaldun, S. Pudjiastuti, I. Rahayu, C.L. Nathanael, D. Oktaverina, M.S. Semboor, Macromolecular Symposia, 327(1), 80(2013), DOI:10.1002/masy.201350509

3. R.E. Rosli, A.B. Sulong, W.R.W. Daud, M.A. Zulkifley, T. Husaini, M.I. Rosli, E.H. Majlan, M.A. Haque, International Journal of Hydrogen Energy, 42(14), 9293(2017), DOI: 10.1016/J.IJHYDENE.2016.06.211

4. Y. Gao, G.P. Robertson, M.D. Guiver, X. Jian, S.D. Mikhailenko, K. Wang, S. Kaliaguine, Journal of Membrane Science, 227(1-2), 39(2003), DOI:10.1016/J.MEMSCI.2003.08.020

5. X. Ren, M.S. Wilson, S. Gottesfeld, Journal of Electrochemical Society, 143(1), L12(1996), DOI: $10.1149 / 1.1836375$

6. P. Xing, G.P. Robertson, M.D. Guiver, S.D. Mikhailenko, K. Wang, S. Kaliaguine, Journal of Membrane Science, 229(1-2), 95(2004), DOI:10.1016/J.MEMSCI.2003.09.019

7. S. Wang, G. Sun, G. Wang, Z. Zhou, X. Zhao, H. Sun, X. Fan, B. Yi, Q. Xin, Electrochemical Communication, 7(10), 1007(2005), DOI:10.1016/J.ELECOM.2005.07.003

8. A. Realpe, Y. Pino, M.T. Acevedo, International Journal of ChemTech Research, 9(11), 157(2016)

9. H.M. Li, J.C. Liu, F.M. Zhu, S.A. Lin, Polymer International, 50(4), 421(2001), DOI:10.1002/pi.646

10. S. Mulijani, K. Dahlan, A. Wulanawati, International Journal of Materials, Mechanics and Manufacturing, 2(1), 36(2014), DOI:10.7763/IJMMM.2014.V2.95

11. B.K. Nath, A. Khan, J. Chutia. Material Research Bulletin, 70, 887(2015), DOI: 10.1016/J.MATERRESBULL.2015.06.028

12. N. Carretta, V. Tricoli, F. Picchioni, Journal of Membrane Science, 166(2), 189(2000), DOI: $10.1016 / \mathrm{S} 0376-7388(99) 00258-6$

13. W. Lee, H. Kim, H. Lee, Journal of Membrane Science, 320(1-2), 78(2008), DOI: 10.1016/J.MEMSCI.2008.03.066

14. J.P. Shin, B.J. Chang, J.H. Kim, S.B. Lee, D.H. Suh, Journal of Membrane Science, 251(1-2), 
247(2005), DOI:10.1016/J.MEMSCI.2004.09.050

15. M. Arroyo, M.A. López-Manchado, J.L. Valentín, J. Carretero, Composites Science and Technology, 67(7-8), 1330(2007), DOI:10.1016/J.COMPSCITECH.2006.09.019

16. Z. Peng, L.X. Kong, S.D. Li, Y. Chen, M.F. Huang, Composites Science and Technology, 67(15-16), 3130(2007), DOI:10.1016/J.COMPSCITECH.2007.04.016

17. K. Sanguansap, T. Suteewong, P. Saendee, U. Buranabunya, P. Tangboriboonrat, Polymer (Guildf), 46(4), 1373(2005), DOI: 10.1016/J.POLYMER.2004.11.074

18. S. Hendrana, M.S. Semboor, C.L. Natanael, I. Rahayu, M. Mashadi, S.Sudirman, Jurnal Sains Materi Indonesia, 18(4), 147(2018), DOI:10.17146/jsmi.2017.18.4.4130

19. I. Gustian, Rasayan Journal of Chemistry, 10(3), 689(2017), DOI:10.7324/RJC.2017.1031716

20. L. Fukuhara, N. Kado, K. Kosugi, P. Suksawad, Y. Yamamoto, H. Ishii, S. Kawahara, Solid State Ionics, 268, 191(2014), DOI: 10.1016/J.SSI.2014.09.040

21. Z. Zeng, W. Ren, C. Xu, W. Lu, Y. Zhang, Y. Zhang, Journal of Polymer Research, 17(2), 213(2010), DOI: $10.1007 /$ s10965-009-9307-6

22. Y.M. Puerta, A.R. Jiménez, M.A. Morantes, International Journal of Engineering Trends and Technology, 7(1), 1(2014), DOI:10.14445/22315381/IJETT-V7P216

23. A. Realpe, N. Mendez, M. Acevedo, International Journal of Engineering and Technology, 6(5), 2435(2014)

24. S. Dharmadhikari, D. Ghime, V. Kumar, Rasayan Journal of Chemistry, 12(4), 2103 (2019), DOI: $10.31788 /$ RJC.2019.1245422

25. P. Suksawad, K. Kosugi, Y. Yamamoto, K. Akabori, H. Kuroda, S. Kawahara, Journal of Applied Polymer Science, 122(4), 2403(2011), DOI:10.1002/app.34352

26. N. Jamaluddin, M.J.M. Yusof, I. Abdullah, S.F.M. Yusoff, Rubber Chemistry and Technology, 89(2), 227(2016), DOI:10.5254/rct.15.84869

27. N.H.A. Azhar, H.M. Rasid, S.F.M. Yusoff, Chemical modifications of liquid natural rubber. In: $A I P$ Conference Proceedings, Vol.1784, AIP Publishing LLC (2016), pp. 030024, DOI: $10.1063 / 1.4966762$

28. P. Juntuek, C. Ruksakulpiwat, P. Chumsamrong, Y. Ruksakulpiwat, Journal of Applied Polymer Science, 122(5), 3152(2011), DOI:10.1002/app.34324

29. S.T. Gonggo, C.L. Radiman, B. Bundjali, I.M. Arcana, ITB Journal of Science, 44(3), 285(2012), DOI: 10.5614 itbj.sci.2012.44.3.8

30. A. Das, D.Y. Wang, K.W. Stöckelhuber, et al. Rubber-Clay Nanocomposites: Some Recent Results. In: Springer, Berlin, Heidelberg, 85 (2010), DOI:10.1007/12_2010_96

31. E. Carone, U. Kopcak, M. Gonçalves, S. Nunes, Polymer (Guildf), 41(15), 5929(2000), DOI: 10.1016/S0032-3861(99)00800-9

32. M.I. Fathurrohman, B. Soegijono, E. Budianto, K. Yoneda, Indonesian Journal of Natural Rubber Research, 31(1), 45(2013)

33. F. Schön, R. Thomann, W. Gronski, Macromolecule Symposia, 189(1), 105(2002), DOI: $10.1002 /$ masy. 200290000

34. B. Herzog, D.J. Gardner, A.R. Lopez, B. Goodell, Journal of Applied Polymer Science, 97(6), 2221(2005), DOI:10.1002/app.21868

35. V.G. Geethamma, G. Kalaprasad, G. Groeninckx, S. Thomas, Composites Part A: Applied Science and Manufacturing, 36(11), 1499(2005), DOI:10.1016/J.COMPOSITESA.2005.03.004

36. M. Baboo, M. Dixit, K. Sharma, N.S. Saxena, Thermochimica Acta, 502(1-2), 47(2010), DOI: $10.1016 /$ J.TCA.2010.02.004

37. A. Morin, F. Xu, G. Gebel, O. Diat, International Journal of Hydrogen Energy, 36(4), 3096(2011), DOI: 10.1016/J.IJHYDENE.2010.11.070

38. D.N. Son, H. Kasai, The European Physical Journal E., 29(4), 351(2009), DOI:10.1140/epje/i200910500-1

39. K. Jiao, X. Li, Progress in Energy and Combustion Science, 37(3), 221(2011), DOI:10.1016/J.PECS.2010.06.002

[RJC-5616/2019] 